\title{
As ambições e estratégias das grandes potências na Ásia Central: o realismo da Rússia e da União Europeia*
}

\section{The goals and strategies of the great po- wers in central Asia: the realism of Russia and the European Union}

Paulo Duarte

* Recebido em: 19.09 .2014 Aprovado em: 30.09.2014

1 Doutorando em Relações Internacionais na Université Catholique de Louvain, Bélgica. Investigador do Instituto do Oriente em Lisboa. Bolseiro da Fundação Calouste Gulbenkian. E-mail: duartebrardo@gmail.com.

\section{Resumo}

O objetivo do presente artigo consiste em contribuir para o aumento do conhecimento acerca de uma região do mundo remota, mas de extrema importância no contexto geopolítico e económico da atualidade: a Ásia Central. O argumento central é o de que as potências/agrupamentos externos (a União Europeia e a Rússia) demonstram um interesse de caráter fundamentalmente económico (a busca de recursos energéticos) na região, perseguindo políticas de natureza predominantemente realista face a esta. Em alternativa à observação participante e não participante, técnicas de difícil aplicação ao presente objeto de estudo, recorreu-se à entrevista semiestruturada. A pesquisa de campo foi efetuada, através de entrevistas realizadas fundamentalmente na Ásia Central. Convictos de que o comportamento dos Estados, o poder ou a influência não são suscetíveis de se traduzir em realidades tangíveis ou fórmulas matemáticas, assumimos que o recurso ao método qualitativo, através da análise hermenêutica, é, indiscutivelmente, a metodologia em que assenta a presente investigação.

Palavras-chave: Ásia Central. União Europeia. Rússia.

\begin{abstract}
The aim of this paper is to contribute to increase knowledge about a remote region of the world, but of utmost importance in the geopolitical and economic context of today: Central Asia. The central argument is that the great powers (the European Union and Russia) demonstrate a predominantlyeconomic interest (the search for energy resources) towards the region, pursuing fundamentally realistic-driven policies with regard to it. Alternatively to the participant and non-participant observation, which are difficult techniques to apply to this object of study, we resorted to the semistructured interview. The field research was done through interviews conducted predominantly in Central Asia. Convinced that the behaviour of the states is not likely to translate into tangible realities or mathematical formulas, we assume that the use of the qualitative method, through the hermeneutic analysis, is the methodology supporting this investigation.
\end{abstract}

Keywords: Central Asia. European Union. Russia. 


\section{Introdução}

Várias correntes geopolíticas destacam a proeminência da Ásia Central no quadro da geoestratégia e economia mundiais. Autores, como H. Mackinder (2004) ou Z. Brzezinski (1998), salientaram a importância do 'Heartland' (Balcãs Euroasiáticos), enquanto 'eixo do mundo' e espaço geopolítico que confere poder e influência à potência que dele se apropriar.

Nos últimos anos, principalmente devido às descobertas de importantes reservas energéticas na região e aos desenvolvimentos ligados à segurança mundial e regional, várias correntes de pensamento, têm reforçado os pressupostos de Mackinder e Brzezinski. O próprio debate acerca do conceito de segurança, que emergiu no pós-Guerra Fria veio conferir outras dimensões - ultrapassando a visão estato-cêntrica e anárquica do sistema internacional defendida por autores como Morgenthau (1978) - à ideia de segurança. Efetivamente, a corrente realista, para a qual a segurança aparecia inseparavelmente ligada à posse e uso das capacidades militares, poder e interesses dos atores estatais, cede progressivamente (KEOHANE, 2000). Os estudos sobre a segurança, nos anos 90, vieram convertê-la num conceito global. Barry Buzan destacou-se nessa corrente que reivindicava uma dimensão mais ampla para o conceito de segurança. Este seria composto, doravante, por uma vertente militar, política, económica (compreendendo a segurança energética) e ambiental (BUZAN, 1991). Estava aberto o caminho à securitização do fenómeno energético. Para especialistas como Daniel Yergin (2006) falar em segurança energética pressupunha assegurar uma oferta de energia estável, a preços razoáveis. Outras definições do conceito seriam elaboradas posteriormente, refletindo quer a evolução das várias correntes teóricas, quer os interesses de produtores e consumidores energéticos. Apesar das múltiplas interpretações do conceito por parte das diferentes correntes teóricas, todas elas convergem quanto ao pressuposto fundamental de que um país deve ter acesso aos seus recursos energéticos de forma permanente, correndo um risco mínimo de que estes se esgotem. Ora, ao percorrermos a literatura existente verificamos que a Ásia Central constitui uma alternativa importante na diversificação energética europeia ou russa.

Vários autores argumentam que a riqueza energética da Ásia Central transformou a região numa encruzilhada de tensão entre Estados, de competição entre empresas e atores regionais (EDWARDS, 2003). Consequentemente, as grandes potências e multinacionais querem estar presentes nesta corrida à energia. $\mathrm{O}$ acesso às reservas petrolíferas, a rota dos oleodutos e o debate sobre quem deve construí-los inserem-se nas premissas daquilo a que alguns especialistas chamam 'Novo Grande Jogo', ou, antes, o 'regresso do Grande Jogo’. Este comporta também uma lógica de defesa e segurança militar, e não apenas de competição energética, reforçando o interesse da Ásia Central para as potências regionais e extraregionais.

Uma breve consideração acerca do realismo. O realismo pode ser concebido como a teoria política do nacionalismo económico: a ideia central é que atividades económicas governamentais devem permanecer subordinadas ao objetivo de construção do Estado (SIITONEN, 1990). Baseado em tais postulados, o paradigma realista dominou consideravelmente os debates e a pesquisa em Relações Internacionais, no pós-Guerra, nos Estados Unidos e na Europa. Na perspetiva realista, a sociedade internacional encontra-se, fundamentalmente, num "estado de anarquia" hobbesiano, movida pela "busca de poder" (SIITONEN, 1990, p. 20). De facto, “o realismo político carateriza uma sociedade internacional essencialmente anárquica, na qual os atores subsistem através da gestão possível de um inevitável 'estado de natureza"' (SANTOS, 2007, p. 243). Os atores agem de acordo com os velhos postulados do realismo e da realpolitik (BLANK, 1999). Por outro lado, muitas das medidas que eles tomam, e que visam aumentar a sua influência política, inscrevem-se na própria lógica da economia de mercado. As escolas realista e neorrealista, admitem, portanto, que "a sobrevivência do Estado nacional constitui a finalidade última da governação desenvolvida pelo aparelho do poder"; [...] "Todas as políticas, são definidas como uma "luta pelo poder" (SANTOS, 2007, p. 242). Neste sentido,

o poder é concetualizado como um meio e um fim em si mesmo, e o seu significado geral é o da capacidade para influenciar ou alterar o comportamento de outros numa direção desejada, ou alternativamente, a capacidade de resistir a tais influências sobre os comportamentos próprios. (SANTOS, 2007, p. 242).

Depois de introduzidos os postulados realistas, bem como a importância geopolítica e económica da Ásia Central, passaremos a desenvolver o nosso argumento 
central, isto é, o de que as potências/agrupamentos externos (a União Europeia e a Rússia) demonstram um interesse de caráter fundamentalmente económico (a busca de recursos energéticos) na região, perseguindo políticas de natureza predominantemente realista face a esta.

Convictos de que o comportamento dos Estados, o poder ou a influência não são suscetíveis de se traduzir em realidades tangíveis ou fórmulas matemáticas, assumimos que o recurso ao método qualitativo, através da análise hermenêutica, é, indiscutivelmente, a metodologia em que assenta a presente investigação. Neste sentido, é imperativo penetrar na esfera da subjetividade, isto é, da compreensão da causalidade inerente à ação dos diversos atores, que nos chega através da análise de toda uma panóplia de artigos científicos, monografias, teses, entre outras fontes disponíveis face à temática em estudo, de forma a procurar entender o que leva determinado ator a agir desta ou daquela maneira. Em alternativa à observação participante e não participante, técnicas de difícil aplicação ao presente objeto de estudo, recorreu-se à entrevista semiestruturada. A pesquisa de campo foi efetuada, através de entrevistas realizadas fundamentalmente na Ásia Central a figuras-chave no âmbito da problemática estudada. As entrevistas foram efetuadas no âmbito de duas deslocações ao terreno centro-asiático, uma de 3 a 11 de setembro de 2011 ao Cazaquistão, a convite da Diretora do Suleimenov Institute, em Almaty, e a segunda deslocação de 28 de setembro a 18 de outubro de 2012 a dois outros países, além do Cazaquistão: Quirguistão e Tajiquistão (entre as principais cidades visitadas destaquemos Almaty, Bishkek, Naryn, Osh, Dushanbe). A planificação das duas deslocações à Ásia Central envolveu uma pesquisa exaustiva e morosa de universidades, especialistas, diplomatas, docentes, Organizações Não Governamentais, tendo a Rede Aga Khan, entre muitos outros atores, fornecido um apoio considerável, não só ao nível da seleção de especialistas locais, como na facilitação de entrevistas à distância, por via telefónica, bem como ainda na visita aos vários polos da University of Central Asia (no Cazaquistão, Quirguistão e Tajiquistão).

Às dificuldades inerentes à seleção e contato prévio com entidades e especialistas locais, acresce a barreira linguística, a obtenção de vistos e a ausência de embaixada de Portugal em cada uma das Repúblicas centro-asiáticas, devendo sempre ter de recorrer a embaixadas em países terceiros ${ }^{2}$ ), para tratar da burocracia caraterística de países como o Cazaquistão, que requer cartas de convite, entre outros procedimentos. Uma outra dificuldade prende-se com a própria natureza autoritária das Repúblicas centro-asiáticas, que faz com que a deslocação de um investigador a estes países suscite eventuais suspeitas por parte das autoridades locais, as quais se negam, frequentemente, a emitir vistos de estadia.

Um investigador depara-se, por conseguinte, com vários riscos neste tipo de países (já que o regime é praticamente omnipresente na vida dos cidadãos e instituições), sendo que o mesmo tem de investir, por conseguinte, um tempo bastante considerável na preparação das suas deslocações para evitar, ou, pelo menos, reduzir a possibilidade de que algo corra menos bem (porém, não conseguimos ${ }^{3}$, para focar outro exemplo, evitar ser retidos, a cerca de cinco mil metros de altitude, pelos guardas fronteiriços no Tajiquistão que, ao vedarem-nos a entrada no seu país, acabaram, ainda que indiretamente, por fazer com que tivéssemos de pensar num 'plano B', que consistiu em viajarmos até à ponta oposta do Quirguistão para tentarmos atravessar aí a fronteira para o Tajiquistão (desta vez, bem-sucedidos). ${ }^{4}$ Uma outra dificuldade inerente à recolha da informação, já não tanto ligada às restrições ou ao autoritarismo, tem que ver com uma outra ordenação do território (diferente do caso europeu, por exemplo), que explica que para nós, ocidentais, tivesse sido muito complexo, em vários casos, encontrar as moradas previamente fornecidas pelos entrevistados. Ou seja, por diversas vezes, quer no Cazaquistão, Quirguistão e Tajiquistão constatámos que as habitações não estão numeradas

2 Neste caso, isto é, no âmbito das duas deslocações ao terreno, optou-se por recorrer às Embaixadas do Cazaquistão, Quirguistão e Tajiquistão na Bélgica.

3 Utiliza-se aqui o plural pelo facto de o autor do presente artigo, enquanto doutorando, ter viajado com o seu supervisor de tese, o Professor Doutor Marcos Farias Ferreira.

4 A 14 de outubro de 2012, estando a fronteira tajique - chamada Bardaba, a quase 5000 metros de altitude - para Murgarb fechada ao trânsito de estrangeiros, optámos por cancelar os planos de ida a Khorog. Dormimos numa aldeia fronteiriça quirguize (chamada Sary Tash) e partimos no dia seguinte para Osh, com o objetivo de tomarmos a estrada para Batken, e aí tentarmos atravessar a fronteira (desta vez sem grandes complicações burocráticas) para chegarmos a Dushanbe (onde havíamos agendado várias entrevistas) e tomarmos o voo de regresso. 
nem possuem a respetiva caixa postal. Isto levou a que chegássemos atrasados a uma ou outra entrevista, ainda que recorrendo à ajuda de taxistas - eles próprios não sabendo onde se localizavam as moradas fornecidas pelos nossos entrevistados. No caso, por exemplo, do quartel da Organização para a Segurança e Cooperação na Europa (OSCE) em Dushanbe, apenas conseguimos lá chegar porque vimos um automóvel identificado pela sigla desta organização nas proximidades do espaço reservado à mesma. A juntar a todos estes aspetos, julgo ainda ser pertinente mencionar as várias desistências de entrevistados - praticamente confirmados - a poucas semanas da partida para a Ásia Central, o que levou a um repensar de estratégias e a uma nova procura de especialistas a entrevistar. $\mathrm{Na}$ maior parte dos casos, sobretudo no que respeita ao Quirguistão e, mais ainda, ao Tajiquistão), os websites afetos às universidades e institutos locais ora não ofereciam qualquer versão dos seus conteúdos na língua inglesa, ora se encontravam, pura e simplesmente, em manutenção, ou não mais disponíveis. Todos estes aspetos podem, eventualmente, ser reveladores de uma outra visão do mundo e do território, onde o desaparecimento do Estado soviético, causador, frequentemente, de uma certa nostalgia nas gerações mais velhas, acabou por dar lugar a um rol de líderes autoritários, que descuraram o ordenamento do território e o bem-estar da população, em detrimento dos seus próprios interesses pessoais, nos quais o fator petróleo e/ou gás natural veio muitas vezes, trazer um 'falso desenvolvimento', que beneficia elites e certos grupos económicos.

\section{Os objetivos da União Europeia na Ásia Cen- tral}

Nos primeiros anos do seu envolvimento na Ásia Central, a União Europeia não possuía uma interpretação realista acerca da região. Pelo contrário, os seus altos responsáveis eram sobretudo idealistas e dispunham de uma compreensão insuficiente acerca da natureza das sociedades centro-asiáticas e dos seus líderes. Os Estadosmembros da União Europeia pretendiam salvaguardar a independência das novas Repúblicas, eliminar todas as armas nucleares do Cazaquistão, manter a estabilidade, conter o desenvolvimento de regimes fundamentalistas e assegurar que as Repúblicas recém-independentes formulassem políticas pró-ocidentais, e, portanto, em conformidade com o modelo democrático ocidental. Por outro lado, os decisores políticos europeus passariam a preocupar-se com a evolução da democracia pluralista e com a emergência de regimes islâmicos radicais, quer anti-comunistas, quer anti-Ocidente. Neste contexto, durante a última década, a política da União Europeia face à Ásia Central tem vindo a evoluir "de uma atitude de 'indiferença' para uma postura de envolvimento ativo" (WUNDERLICH; BAILEY, 2011, p. 10). No começo dos anos 90, os responsáveis políticos europeus questionavam-se acerca da "real importância da Ásia Central", sendo que, efetivamente,

desde 1991 até meados da década de 90, esta revestia uma importância marginal para a União Europeia, tendência que manteria até 1995/1996, quando Bruxelas acabaria por reconhecer o potencial energético da região e desenvolveria uma política centrada nas questões energéticas relativamente às Repúblicas centro-asiáticas. (HUNTER, 1996, p. 155).

Por outro lado, "os ataques terroristas do 11 de setembro de 2001 viriam a contribuir para que a União Europeia prestasse mais atenção à Ásia Central” (MELVIN, 2008, p. 41).

Embora o então chefe de política externa da União Europeia, Javier Solana, referisse que a prioridade europeia eram os Balcãs, e não a Ásia Central, na prática, Solana viria a enfatizar a importância de uma reavaliação da política de Bruxelas face à Ásia Central, como ilustra bem a frase por si proferida: "temos de começar a repensar a nossa política face aos 'Stans' [aos estões]" (Cit. por ULYANOVSKY, 2001, p.1). A grande viragem na política da União Europeia face à região surgiu quando os seus altos decisores consideraram importante apoiar os países da região a nível económico, e envolvêlos numa cooperação com as instituições europeias. De 1991 a 2001, Bruxelas concedeu 944,4 milhões de euros às Repúblicas centro-asiáticas, as quais viriam a tornar-se membros da Organização para a Segurança e Cooperação na Europa em 1992. Neste mesmo ano, a União Europeia viria a concluir Acordos de Parceria e Cooperação com o Cazaquistão e o Quirguistão e, mais tarde, também com o Uzbequistão. Estes acordos vieram formalizar as relações bilaterais entre a União Europeia e cada Estado parceiro, e forneceram às Repúblicas recémindependentes uma plataforma comum para tratarem de questões económicas, políticas e outros assuntos de interesse coletivo. 
Especialistas como Raquel Freire ${ }^{5}$ (2012), partilham da opinião de que a "União Europeia é um jogador tardio na Ásia Central". Não obstante, Bruxelas tem vindo a intensificar, de forma substancial, o seu envolvimento nas Repúblicas centro-asiáticas, desde que formalizou a sua estratégia regional, em 2007, com vista ao "reforço da ajuda e das relações para o período de 2007-2013" (NICHOL, 2012, p. 7). No entanto, é preciso sublinhar que, "para Bruxelas, a Ásia Central não é uma região prioritária já que, por um lado, não integra a sua vizinhança do leste, nem do sul, nem faz parte dos interesses históricos coloniais de nenhuma potência europeia" (PEYROUSE et al, 2012, p. 5).

De acordo com o docente alemão, Markus Kaiser ${ }^{6}$ (2012), convidado do Departamento de Estudos Europeus da American University of Central Asia (AUCA),"a União Europeia dispõe, hoje, de uma estratégia para a Ásia Central", na qual "a questão da cooperação regional merece especial destaque, bem como a da educação". Para Gorkem Atsungur ${ }^{7}$ (docente convidado do mesmo departamento) (2012),"importa clarificar o que se entende em termos de estratégia [...]; visto que não se pode falar de qualquer estratégia até 2003". O 11 de setembro de 2001, e a dinâmica a ele associada, contribuiu significativamente para a "construção de uma 'estratégia' oficial face à região", sendo que anteriormente, o enfoque concentrava-se essencialmente na "assistência técnica" (ATSUNGUR, 2012). Em 2003 a União Europeia dispunha de um Documento Estratégico de Segurança.

Embora segundo Raquel Freire (2012) exista, agora, "uma estratégia da União Europeia para a Ásia Central", o certo é que "a política de vizinhança da União Europeia" se estendeu "ao Cáucaso, e, portanto, a Geórgia, a Arménia e o Azerbaijão fazem parte dela, mas os países da Ásia Central não". Há que reconhecer, também, que "a região não ocupa nenhuma posição cimeira na agenda de política externa europeia, comparativamente aos países vizinhos da União Europeia e às grandes potências económicas, como a Índia ou a China" (PEYROUSE et al, 2012, p.5). Por outro lado, os autores acrescentam que "os interesses europeus na
Ásia Central são menos substanciais e diretos quando comparados aos da China e, em especial, aos da Rússia" (PEYROUSE et al, 2012, p. 6).

No entendimento de um especialista centro-asiático, Roman Mogilevski ${ }^{8}$ (2012), a União Europeia tem procurado contribuir para o desenvolvimento das relações entre as várias Repúblicas centro-asiáticas, através do mecanismo de "mediação", porém, "a sua capacidade para resolver os assuntos mais importantes tem sido limitada”. Já Armando Marques Guedes ${ }^{9}$ (2011) considera que "a Europa está muito pouco presente, coletivamente, na Ásia Central", até porque, segundo o autor, "em boa verdade, a União Europeia não é um ator político internacional tão forte como quereríamos que fosse, e nem o é no interior do território europeu, e fora ainda menos".

Quer para a União Europeia, quer para as Repúblicas centro-asiáticas, a ideia de um regionalismo 'extrovertido', que contribua para mitigar os constrangimentos geográficos da região, abrindo as Repúblicas centro-asiáticas a várias opções externas, é, naturalmente, mais interessante do que o regionalismo 'introvertido' que, até agora, tem acompanhado a estratégia da União Europeia face à Ásia Central (EMERSON, 2009, p. 1). Tal estratégia é, atualmente, confrontada com os desafios da entrada numa fase multipolar no quadro da governança global, na qual a Índia, a China e a Rússia, e a própria União Europeia, se apresentam como grandes potências emergentes, ou reemergentes, na Eurásia. Este é o principal desafio estratégico do século XXI, ou seja, "o de encontrar formas de garantir algum tipo de ordem normativa/cooperativa, através de uma série de temas políticos, económicos e securitários, baseados numa combinação de multilateralismo e cooperação entre os principais atores" (EMERSON, 2009, p. 1-2). Ora, a Ásia Central estará, "necessariamente, envolvida em muitos destas questões" (EMERSON, 2009, p. 2).

Nos últimos anos, a instabilidade no Médio Oriente, o aumento nos preços da energia e os esforços em reduzir o impacto ambiental na produção e consumo energético contribuíram para que "a questão da segurança do aprovisionamento energético" se tenha convertido
5 Raquel Freire (2012), Entrevista pessoal, Coimbra. Docente de Relações Internacionais na Universidade de Coimbra (Portugal) e autora de vários artigos sobre estudos pós-soviéticos.

6 Markus Kaiser (2012). Entrevista pessoal, Bishkek.

7 Gorkem Atsungur, (2012). Entrevista pessoal, Bishkek.
8 Roman Mogilevski (2012). Entrevista pessoal. Bishkek. Diretor-Executivo no CASE - Quirguistão e Consultor de vários organismos multilaterais regionais e extra-regionais.

9 Armando Marques Guedes (2011). Entrevista Pessoal. Lisboa. Docente de Direito na Universidade Nova de Lisboa. 
"numa das principais preocupações das nações europeias" (RATNER et al, 2013, p. 1). Tais preocupações foram, naturalmente, reforçadas devido à disseminação de um novo 'nacionalismo energético' em países produtores de energia como a Rússia, a qual tem enveredado por políticas cada vez mais assertivas, desde que Putin foi eleito Presidente pela primeira vez.

De acordo com o Cônsul Fernando Melo Antunes $^{10}$ (2012), a Ásia Central é, do ponto de vista geoestratégico, importante para a União Europeia na medida em que representa "uma fonte alternativa à energia russa”. A Europa está a tornar-se cada vez mais dependente dos recursos energéticos estrangeiros, sendo que "os índices mais elevados de dependência energética, em 2010, foram registados para o petróleo (85.2 \%) e para o gás natural (62.4\%)” (EUROSTAT, 2012: para. 8). De acordo, ainda, com a mesma fonte,

o crescimento, na última década (entre 2000 e 2010), da dependência face aos países não-membros da [União Europeia] em termos de abastecimento de combustíveis sólidos $(29.2 \%)$ e gás natural $(27.6 \%)$ foi mais rápido do que para o petróleo (12.7\%)" (EUROSTAT, 2012, \$ $8^{\circ}$ ).

Desde 2003, “as importações energéticas dos países europeus foram superiores à sua produção primária; por outras palavras, mais de metade do consumo interno bruto de energia dos Estados da União Europeia foi satisfeito através do recurso a importações" (EUROSTAT, 2012, $\$ 8^{\circ}$ ).

No cenário atual, “a União Europeia tem tendência a ultrapassar os Estados Unidos, enquanto maior importador de petróleo do mundo, em 2015" (AGÊNCIA INTERNACIONAL DE ENERGIA, 2011, p. 5). Parafraseando as palavras do antigo Presidente norte-americano George W. Bush, "se os Estados Unidos podem estar viciados em petróleo, a Europa está, decididamente, viciada em petróleo do Médio Oriente" (THE WASHINGTON POST, 2006, § 20º).

Num contexto em que a questão energética é entendida como uma das sete prioridades da União Europeia, é de sublinhar os esforços diplomáticos dos últimos anos, por parte desta, no campo das relações energéticas, ao nível da realização de encontros com os líderes centro-asiáticos. Neste sentido, têm vindo

10 Fernando Melo Antunes (2012). Entrevista pessoal, Lisboa. Fernando Melo Antunes é, desde maio de 2011, Cônsul Honorário do Cazaquistão em Portugal. a ser assinados Memorandos de Entendimento com várias Repúblicas centro-asiáticas, com o objetivo de proporcionar às companhias petrolíferas europeias um acesso mais diversificado aos recursos energéticos. Não obstante, os resultados ainda permanecem modestos no que respeita à concretização de projetos do foro energético com os Estados da região. A este respeito,

a União Europeia possui poucos projetos concretos a apresentar, tanto no que concerne ao diálogo com as Repúblicas centro-asiáticas ricas em energia - Turquemenistão, Uzbequistão ${ }^{11}$ com o objetivo de aumentar a exploração dos recursos energéticos [desses países], como no que diz respeito às importações de energia propriamente ditas (BOONSTRA et al, 2009, p.1).

No entendimento de uma especialista cazaque, Assel Rustemova ${ }^{12}$ (2011), a União Europeia “até pode estar interessada na Ásia Central", mas o certo é que "não dispõe de qualquer influência na região". A autora destaca o caso do projeto Nabucco, o qual "está a tentar convencer o Turquemenistão e o Azerbaijão a aderir a este”, embora "a Rússia tenha vindo a procurar impedir a continuidade do projeto" (RUSTEMOVA, 2011).

Ainda existe, na prática, um ceticismo considerável quanto à real importância da União Europeia, enquanto jogador na corrida aos recursos energéticos centroasiáticos. Os mais céticos acreditam, quanto muito, que "as importações de gás natural provenientes da Ásia Central dariam para suprir apenas 3 a $4 \%$ das necessidades energéticas europeias" (BOONSTRA et al, 2009 , p. 1). Por outro lado, eles interrogam-se sobre se vale realmente a pena "insistir em importar petróleo e gás natural, através de oleodutos e gasodutos dispendiosos e sensíveis, contornando a Rússia”, quando

a União Europeia poderia procurar fazer da Rússia um parceiro confiável, reforçando, ao mesmo tempo, os laços energéticos com o Médio Oriente e o continente africano, os quais, além de possuírem uma infraestrutura energética mais desenvolvida, são, do ponto de vista geográfico, mais próximos da Europa do que a Ásia Central" (BOONSTRA et al, 2009, p. 1)

Acrescente-se, por outro lado, que ao escolher o caminho da Ásia Central, a União Europeia poderá estar a arriscar as relações com o seu grande parceiro russo,

11 À exceção do Cazaquistão.

12 Axel Rustemova. (2011). Entrevista pessoal. Almaty. Especialista cazaque em Relações Internacionais e questões centro-asiáticas. 
do qual provém uma parte significativa da energia que consome. Note-se, igualmente, que a União Europeia é um não-competidor se a compararmos a uma China e Rússia, mais envolvidas na região. Na verdade, comparativamente a Pequim e a Moscovo, a União Europeia não possui experiência histórica significativa em termos de interação direta e/ou indireta com a Ásia Central, e os interesses da União Europeia na região revelam-se, atualmente, muito menos acentuados e estáveis quando comparados aos da Rússia e da China. Não surpreende, portanto, que especialistas como Armando M. Guedes (2011) sublinhem, na prática, que a "Europa tem mais força nas ex-colónias, em África, do que na Ásia Central”.

Importa, talvez, questionarmo-nos se será realista esperar resultados concretos em termos de importações energéticas da Ásia Central para a União Europeia. O Turquemenistão, que possui vastas reservas de gás natural, e o Uzbequistão (com menor potencial energético que o vizinho Turquemenistão, poderão, a longo prazo, "vir a colocar problemas (incómodos) para a União Europeia no que respeita à confiabilidade do aprovisionamento, mas também, ao transporte do gás para os mercados europeus" (BOONSTRA et al, 2009, p. 1). Note-se, a este respeito, que à localização do Uzbequistão - um pouco mais distante da Europa que o Turquemenistão - acresce, ainda, o facto de, contrariamente ao Turquemenistão, não ser um Estado litoral do Cáspio, o que fará com que o transporte energético para a Europa fique dependente da Rússia ou dos vizinhos Cazaquistão ou Turquemenistão. Mas importa ainda referir que a política externa uzbeque se tem reveladofrequentemente instável, favorecendo, por vezes, a Rússia, outras vezes os Estados Unidos e a União Europeia (SHIRIEV, 2012). Por sua vez, o Turquemenistão - que está ligado ao Cáspio - poderia,

em teoria, exportar gás natural através de um gasoduto funcionando num corredor meridional (que levará muitos anos a construir), suscetível de ser conetado à infraestrutura logística de países como o Azerbaijão e/ou a Turquia, de modo a servir o Ocidente. (BOONSTRA et al, 2009, p. 1).

$\mathrm{Ou}$, em alternativa, "deverão ser realizados investimentos consideráveis para que o Turquemenistão seja capaz de transportar gás natural liquefeito por navio" (BOONSTRA et al, 2009, p. 1). Contudo, o Governo de Berdimuhamedov permanece, apesar dos sinais de relativa abertura, um regime ainda bastante 'imprevisível' na relação com o exterior.
Todos estes pontos, acima mencionados, têm sido alvo de uma constante atenção por parte da União Europeia, na qual subsistem várias dúvidas, interrogações e desacordo sobre como abordar e solucionar estas questões. No campo da segurança energética, Bruxelas tem vindo a realizar vastos diálogos com o Turquemenistão e o Cazaquistão. É de referir aqui que

o Memorando de Entendimento (de caráter não-vinculativo) que a União Europeia assinou, em 2008, com o Turquemenistão, que prevê a aquisição de gás”, o qual é suscetível de se enquadrar no seu "conceito de 'corredor meridional' de diversificação de abastecimentos em gás natural. (EMERSON; BOONSTRA, 2010, p. 3).

Apesar de Bruxelas ter iniciado conversações políticas, de caráter energético, com o Cazaquistão e o Turquemenistão, na prática, "a maior parte das iniciativas não foram além de projetos técnicos limitados e de um diálogo politico de âmbito geral (pouco concreto)" (FRIDE, 2011, p. 3). O diálogo energético cobre uma vasta gama de tópicos: "infraestruturas, energias renováveis, eficiência energética, e, numa perspetiva de longo prazo, o debate sobre o possível aprovisionamento de gás natural, utilizando o Mar Cáspio como corredor de trânsito" (FRIDE, 2011, p. 15).

O corredor meridional proposto consiste em dois projetos. A peça central é Nabucco, que visa ligar Erzerum, na Turquia, a Baumgarten an der March, na Áustria, tendo sido projetado para transportar "até 31 biliões de metros cúbicos $(\mathrm{bcm})$ de gás natural anualmente, a partir de 2014-16 para a Europa Central" (CLANCY, 2010, $\$ 39^{\circ}$ ). Nabucco cobrirá "aproximadamente $5 \%$ da procura de gás europeia" (LIVANIOS, 2012, p. 5). O projeto Nabucco representa uma oportunidade para a União Europeia diversificar as suas fontes de gás natural e diminuir a sua dependência face às importações de gás natural russo (ROWLEY, 2009, $\$ 1^{\circ}$ ). O segundo projeto consiste no Interconetor de Gás Turquia-Grécia-Itália, que abastece, atualmente, $0.5 \mathrm{bcm}$ por ano à Grécia, mas será expandido com o objetivo defornecer 3.5 bcm à Grécia, e 8 bcm à Itália, em 2014 (WINROW, 2009).

De entre os pontos a sublinhar na política da União Europeia para uma nova parceria face à Ásia Central, é de destacar a questão da estabilidade e da segurança. Apesar de ser uma iniciativa conjunta da União Europeia, a mesma é fruto de esforços conduzidos, essencialmente, pela Alemanha. A Alemanha foi o primeiro país europeu a reconhecer a independência do Cazaquistão, Quirguis- 
tão, Tajiquistão, Turquemenistão e Uzbequistão, e, logo em 1992, enviou várias missões diplomáticas para a região (ROUSSEAU, 2012, \$1º). Atualmente, “a Alemanha tem vindo a demonstrar um interesse crescente em forjar relações mais estreitas, quer ao nível político, quer económico, com estas cinco Repúblicas centro-asiáticas" (ROUSSEAU, 2012, $\$ 1^{\circ}$ ).

Apesar de a nova estratégia da União Europeia face à Ásia Central se basear numa maior cooperação e envolvimento na região, na prática, esta produziu (ainda) poucos efeitos concretos no domínio da democracia, Estado de Direito, boa governança e direitos humanos (AUBERT, 2012). Tal fragilidade tem sido ilustrada pela “incapacidade de a União Europeia alcançar qualquer progresso em matéria de direitos humanos no Uzbequistão", apesar das sanções que impôs no país após a repressão governamental em Andijan, em 2005 (CORNELL, 2007, p. 19). Também no Turquemenistão, a União Europeia tem sido, até ao presente, incapaz de melhorar a situação catastrófica que ameaça os direitos humanos. No que concerne a possíveis 'sanções' pelo não-cumprimento das exigências/requerimentos da União Europeia na região, resta a Bruxelas pouco mais a fazer além da possibilidade de reduzir a sua contribuição financeira para a região. Contudo, "a existência de importantes recursos energéticos nos países mais autoritários da região gera receitas elevadas", acabando por "limitar o impacto de tais sanções" (AUBERT, 2012, p. 13).

Especialistas como Raquel Freire (2012), sublinham que a existência de "numerosas críticas à forma como a União Europeia se tem envolvido [na Ásia Central]", sendo que o que deveria ser, supostamente, um sistema de "corresponsabilidade" nas relações com a região, tem revelado um pendor relativamente "impositivo", por parte da União Europeia. Com efeito, Freire (2012) tem, algumas dúvidas sobre se, de facto, a União Europeia possui uma "estratégia", uma vez que no seu entendimento, não existe "uma politica bem delineada" face à Ásia Central. Também para Gorkem Atsungur (2012), em bom rigor, não se trata de uma estratégia, mas de "uma política de encontros regulares", já que "é muito difícil afirmar que existe um interesse europeu, porque a própria União Europeia é uma entidade muito dividida”.

\section{Os objetivos da Rússia na Ásia Central}

relações com os Estados da região, quanto mais não seja porque estes fizeram parte da antiga União Soviética durante mais de sete décadas. Por outro lado, "desde o fim do século XIX, até meados da década de 90, a Ásia Central era quase domínio exclusivo da Rússia czarista, soviética e pós-soviética” (ROUSSEAU, 2011, \$1º). Assim se compreende que os laços demográficos, culturais e económicos tenham resistido à independência política no início dos anos 90. Efetivamente, o peso da cultura russa ainda é dominante na região (BUCKLER, 2009). A este respeito, "Moscovo continua a influenciar muitos processos e/ou dinâmicas na Ásia Central”, de acordo com "os seus próprios interesses", e, em certa medida, "orienta as economias centro-asiáticas" (GARIBOV, $\left.2013, \$ 9^{\circ}\right)$. Neste

espaço do espaço pós-soviético", a Rússia utiliza os laços humanos e económicos, a influência da língua, as bases militares, e os mecanismos institucionais multilaterais, com o objetivo de manter uma presença de destaque na Ásia Central” (TOMÉ, 2007, \$1).

Muitos membros das elites económicas e políticas centro-asiáticas financiam os estudos dos seus filhos em universidades russas. Por outro lado, muitos russos vivem nos Estados da região, particularmente no Cazaquistão, onde constituem mais de $30 \%$ da população. Acrescentese que cerca de duas décadas depois da independência, as economias destes países continuam a depender consideravelmente da Rússia, sobretudo no que diz respeito ao setor energético. Muitos, em Moscovo, ainda concebem a região como esfera de influência - do passado e do futuro - da Rússia, apesar de os especialistas e decisores políticos russos reconhecerem, claramente, as raízes islâmicas da Ásia Central, as aspirações chinesas e a influência ocidental sobre a região (LUFT; KORIN, 2009). Azad Garibov comunga, igualmente, deste ponto de vista, argumentando que "a Rússia entende os limites da sua influência - ela pode ser relativamente mais importante do que outros atores, mas não um

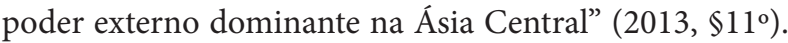
Portanto, neste jogo, "Moscovo espera continuar a ser o principal parceiro da Ásia Central, embora ciente de que a sua presença já não é exclusiva na região" (GARIBOV,

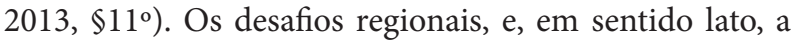
própria conjuntura regional, mudaram. De facto, “a maioria dos especialistas russos admite que num contexto cada vez mais globalizado, o monopólio geopolítico do Kremlin, na Ásia Central, é um cenário completamente 
irrealista” (TORBAKOV, 2008, \$4º). Não obstante, “a Rússia tenderá a procurar formas de limitar a influência dos Estados Unidos na região, enquanto tem sob controlo as ambições centro-asiáticas da China" (TORBAKOV, 2008, $\left.\$ 4^{\circ}\right)$. Além disso, é preciso reconhecer, todavia, que "a presença geopolítica russa nesta vasta região permanece forte”, sendo que, por ora, “a Rússia é (para todos os efeitos) o ator externo mais influente na região" (GARIBOV, 2013, \$12º).

Narana Coissoró ${ }^{13}$ (2010) partilha, porém, de uma visão mais limitativa da influência russa na Ásia Central, segundo a qual "Moscovo já não beneficia de um controlo significativo sobre estas Repúblicas e, por outro lado, os Estados Unidos são quase desconhecidos no panorama geral destes países, embora tenham estabelecido relações diplomáticas.”

Segundo o autor, é, pois, à China que cabe o papel de "interlocutor principal", sendo que "Pequim não manifesta quaisquer ambições expansionistas em relação às Repúblicas centro-asiáticas, na medida em que tal perturbaria o equilíbrio regional” e o próprio “crescimento económico chinês” (COISSORÓ, 2010). Por ora, “o comportamento da Rússia, na Ásia Central, funda-se numa postura (muito) mais pragmática, diretamente relacionada com os seus interesses económicos e securitários" (GARIBOV, 2013, \$11º). O facto de a Rússia ter sido a potência colonizadora da Ásia Central apresenta aspetos positivos e negativos. Por um lado, o longo período de convivência entre colonizador e colónias legou uma linguagem, história, cultura e sentimentos de pertença comuns às Repúblicas centroasiáticas. Já no que respeita aos aspetos negativos desta relação, eles manifestam-se ao nível das "sensibilidades políticas" e das "interpretações culturais dos laços com a potência colonizadora de outrora" (LARUELLE, 2009, p.4). Neste sentido, "os laços entre a Rússia e as Repúblicas centro-asiáticas são complexos, visto que ambos os atores possuem perceções altamente emotivas da relação com o outro" (LARUELLE, 2009, p. 4).

A estratégia de Moscovo face à Ásia Central visa, em primeiro lugar, garantir o papel preponderante da Rússia na exploração, desenvolvimento e transporte dos recursos energéticos centro-asiáticos. Moscovo domina

13 Narana Coissoró (2010), Entrevista pessoal. Lisboa. Narana Coissoró é Presidente do Instituto do Oriente em Lisboa. as exportações de gás natural do Turquemenistão, país que produz "cerca de 70 biliões de metros cúbicos de gás natural por ano, dos quais, aproximadamente dois terços se destinam ao monopólio de gás natural da russa Gazprom” (BBC NEWS ASIA, 2012, \$13º). Além disso, Moscovo desempenha uma missão importante no que concerne ao controlo das exportações de petróleo cazaque (BBC NEWS ASIA, 2012). A este respeito, refira-se que "atualmente, mais de três quartos do petróleo cazaque é exportado através do território russo", nomeadamente por meio dos oleodutos Atyrau-Samara e do Caspian Pipeline Consortium" (VATANSEVER, 2010, p. 19). Por outro lado, as companhias russas têm tido um papel fundamental na exploração das reservas de petróleo e gás natural no Mar Cáspio, em cooperação com os Governos do Azerbaijão, Cazaquistão e Turquemenistão. Importa sublinhar que

a produção russa de gás natural tem sido relativamente fraca nos últimos anos", de modo que "a Rússia tem procurado aumentar as suas importações de gás da região do Cáspio/Ásia Central, onde o adquire a um preço muito baixo, para depois o vender nos mercados europeus por um valor consideravelmente mais elevado. (GORST, 2006, p. 12).

O controlo das rotas de vários oleodutos confere à Rússia poder de negociação, deixando aos Estados regionais, geograficamente isolados, "pouca margem de manobra” (BELTON, 2006, p. 6). A este respeito, “a Rússia irá exercer maior pressão sobre os fornecedores de energia do Cáspio para proteger os seus interesses estratégicos e continuar o seu domínio sobre uma parte substancial do setor energético" (LUFT; KORIN, 2009, p. 119). Daqui resulta que

a política energética russa constituirá uma bar-
reira considerável à integração da região na eco-
nomia global e permanecerá um fator crítico a
respeito da segurança energética dos Estados do
Cáspio e do Ocidente, durante as próximas dé-
cadas. (LUFT; KORIN, 2009, p. 119).

No que concerne aos benefícios económicos, “podem ser obtidos lucros diretos através do domínio e revenda do petróleo e gás natural da região, especialmente quando os preços energéticos disparam no mercado global" (RUOXI DU, 2011, p. 7).

No entendimento de Raquel Freire (2012), “a Rússia tem conseguido aumentar a sua influência no espaço pós-soviético, em detrimento, por exemplo, dos Estados Unidos", sendo que "a questão do Afeganistão 
contribuiu muito a este respeito". Para Stephen Blank ${ }^{14}$ (2011), “a Rússia quer securitizar as suas periferias muçulmanas, de forma a combater o terrorismo e as revoluções islâmicas, que constituem sérias ameaças à sua segurança”. Blank (2011) considera, todavia, que “o sistema económico e político russo não é capaz de sobreviver no seu estado atual, a menos que consiga dominar a economia do petróleo e gás natural na Ásia Central, e competir com os outros jogadores no terreno". Outros comungam inclusive, da tese de que "o sistema russo está a começar a colapsar, não podendo sustentar o atual status quo, nem estar seguro de encontrar uma nova incarnação para si” (SHEVTSOVA, 2013, \$1º). As grandes questões a considerar, no entendimento da Shevtsova, são "em que fase de decadência se encontra o sistema?"; “até que ponto a agonia do seu colapso já começou?"; e, em caso afirmativo, “quanto tempo durará?” $\left(2013, \$ 1^{\circ}\right)$.

Segundo Edward Chow ${ }^{15}$ (2011), “a Rússia vê-se como o poder tradicional na região, concebe a Ásia Central como a sua esfera de influência, sobre a qual gostaria de preservar um papel dominante”. Esta é, também, a visão de que comunga Nargis Kassenova ${ }^{16}$ (2011), segundo a qual a Ásia Central é importante para Moscovo, porque sem ela “a Rússia não poderia ser uma grande potência”. Contrariamente a uma política "em geral, pouco coerente, e muito alvo de improvisação", como fora a política de Yeltsin face à Ásia Central, tem-se verificado, porém, nos últimos anos, “uma constante 'correção do curso' do envolvimento russo na região", guiada pelo “desejo de reafirmação do poder e influência da Rússia no, outrora, espaço soviético" (GIRAGOSIAN, 2006, p. 138). Com efeito, segundo o relatório do Projeto EU-Central Asia Monitoring, "desde 2000 que a influência de Moscovo na elaboração de políticas das Repúblicas centro-asiáticas se tem tornado mais direta”, sendo que "a Rússia voltou a ser, uma vez mais, a principal referência política para os regimes centro-asiáticos, que não se sentem atraídos

14 Stephen Blank (2011). Entrevista através de contato telefónico. Estados Unidos da América. Stephen Blank é especialista no Strategic Studies Institute da U.S. Army War College.

15 Edward Chow, (2011). Entrevista pessoal através de contato telefónico. Estados Unidos da América. Especialista americano em questões centro-asiáticas.

16 Nargis Kassenova, (2011). Entrevista pessoal. Almaty especialista cazaque em Relações Internacionais e questões centro-asiáticas. nem pelos sistemas ocidentais, nem pelo monopartidarismo chinês" (LARUELLE, 2009, p. 4).

A Ásia Central é, por todas estas razões, o campo de projeção de Moscovo, o seu espaço de influência. A Rússia concebe o espaço pós-soviético, no qual se incluem as Repúblicas da Ásia Central, como área prioritária de atuação, e portanto, qualquer intervenção externa é entendida como um confronto direto aos seus interesses primários de política externa (FREIRE, 2012). Contudo, apesar da sua ampla presença no setor militar e estratégico, Moscovo não é capaz de apresentar, atualmente, uma resposta eficaz face aos riscos que minam a estabilidade da região, sejam eles ligados ao terrorismo, ao separatismo, ao extremismo religioso, ao tráfico de estupefacientes, entre outros (EMERSON et al, 2010, p. 39).

A Ásia Central é, entre outros aspetos, importante para Moscovo por motivos securitários, uma vez que “a ameaça do terrorismo e da instabilidade política nas regiões periféricas da Rússia e do antigo mundo soviético - Ásia Central, Cáucaso, Afeganistão, e Médio Oriente - é sério" (TSYGANKOV, 2011, p. 7). A mínima destabilização registada nas Repúblicas centro-asiáticas teria repercussões imediatas na vizinha Rússia (BLANK, 2011). Entre os vários aspetos que preocupam Moscovo, destaque-se "o aumento do narcotráfico na região" (e a respetiva intensificação do consumo de estupefacientes na Rússia);

a perda de controlo sobre a infraestrutura logística (oleodutos e gasodutos) energética, mas também sobre as centrais hidroelétricas, os depósitos de urânio e os locais estratégicos afetos ao complexo militar-industrial; o incontrolável fluxo de migrantes; o receio de perda de acesso direto ao Afeganistão; o receio de diminuição das trocas comerciais com os seus parceiros centro-asiáticos; e, naturalmente, o problema do terrorismo e doseparatismo" (EMERSON et al, 2010, p. 38).

Além disso, Moscovo concebe a proteção das suas fronteiras meridionais com a Ásia Central como um assunto de segurança doméstica. Uma vez que é praticamente impossível a Rússia garantir a segurança dos 7000 quilómetros de fronteira russo-cazaque, tal pressupõe que terá de existir um melhor controlo antes da fronteira, o que atesta a importância da Ásia Central enquanto zona-tampão para a Rússia. Neste sentido, importa sublinhar que a cooperação entre Moscovo e os seus vizinhos centro-asiáticos se realiza, principalmente, no quadro da Organização do Tratado de Segurança 
Coletiva (OTSC), que é “a única instituição, na região, dotada de uma dimensão militar genuína” (LARUELLE, 2009, p. 7).

Heitor Romana" (2012) explica que "para contrabalançar a Organização de Cooperação de Xangai”, Moscovo criou a OTSC, algo que para este especialista

é curioso" na medida em que "a Rússia faz parte da Organização de Cooperação de Xangai, mas a China não é membro da OTSC". No âmbito da OTSC, a força coletiva de intervenção rápida (composta por unidades cazaques, quirguizes, russas e tajiques), é a única força dotada da capacidade para intervir em tempo real (BLANK, 2011, p. 11-12).

No quadro da OTSC são efetuados, anualmente, exercícios militares num dos países membros, onde se simula, por exemplo, operações de combate ao narcotráfico e a ataques terroristas. A cooperação militar entre Moscovo e a Ásia Central permite que os países da região enviem os seus soldados, todos os anos, para as academias militares russas, onde recebem formação (EMERSON et al 2010, p. 39). Por outro lado, "a Rússia tem favorecido a venda de armamento, a preços de mercado doméstico russo, aos Estados da região, e fez ressurgir a cooperação entre complexos militares industriais" (EMERSON et al, 2010, p. 39).

O outro motivo de importância da Ásia Central para a Rússia, está diretamente relacionado com os recursos energéticos existentes na região. A Rússia possui as maiores reservas de gás natural do mundo, com 47 triliões de metros cúbicos, o que representa "cerca de um quarto da totalidade das reservas comprovadas do mundo" (U.S. ENERGY INFORMATION ADMINISTRATION, 2012, $\$ 1^{\circ}$ ). Por outro lado, a Rússia detém "as nonas maiores reservas de petróleo mundiais", cerca de "60 biliões de barris de reservas petrolíferas comprovadas à data de janeiro de 2012" (U.S. ENERGY INFORMATION ADMINISTRATION, 2012, \$5 $)$. Além de todo este potencial energético, “a Rússia é um importante produtor de petróleo e gás natural, preservando o seu estatuto de país de trânsito no que respeita ao transporte de energia desde o Cáucaso e Ásia Central para a Europa”, sendo que "Moscovo permanece determinado a desempenhar um papel fundamental nos mercados energéticos mundiais"

17 Heitor Romana, (2012). Entrevista Pessoal. Lisboa. Docente de Relações Internacionais no ISCSP-Universidade de Lisboa.
(TSYGANKOV, 2011, p. 7). Por outro lado,

do ponto de vista geográfico, a Rússia se situa estrategicamente perto de regiões - Europa e Ásia oriental - cujo consumo energético tem vindo a crescer rapidamente, sendo expetável que a energia constitua uma percentagem substancial das exportações russas e do seu produto interno" (BAHGAT, 2003, p. 30).

A Rússia é o fornecedor mais importante de gás natural da Europa, representando "36\% das importações europeias de gás natural" (RATNER et al 2013, p. 1). Estima-se que o consumo de gás natural da Europa cresça, "enquanto a sua produção doméstica continua a diminuir" (RATNER et al 2013, p. 1). Se a tendência se mantiver, "a dependência europeia face à Rússia, enquanto fornecedor, tenderá a aumentar" (RATNER et al 2013, p. 1).

Desde o final dos anos 90, a subida, cada vez maior, dos preços da energia, bem como a crescente procura energética - sobretudo por parte da Índia e da China - contribuíram para que a Rússia redescobrisse "o poder da energia" enquanto "instrumento político", de forma a "reconquistar o seu estatuto de grande potência", bem como a sua importância geopolítica (GIRAGOSIAN, 2006, p. 138). É, aliás, elucidativo o exemplo a que o mundo assistiu em dezembro de 2005, quando Moscovo decidiu interromper o abastecimento energético à Ucrânia, reivindicando um aumento do preço do gás importado por Kiev. Moscovo consegue influenciar a indústria petrolífera e de gás natural das Repúblicas centro-asiáticas de várias formas:

como parceiro ou investidor em projetos energéticos; enquanto país de trânsito ao qual os Estados da Ásia Central recorrem para exportar os seus recursos; como competidor em muitos destes mercados, e enquanto mercado. (BAHGAT, 2003, p. 150).

Ainda antes da sua primeira eleição à presidência, enquanto Primeiro-Ministro, Vladimir Putin já manifestava um profundo interesse pela "ativação da diplomacia russa no 'estrangeiro próximo' de Moscovo", como atestaram, aliás, as suas diversas visitas oficiais às Repúblicas centro-asiáticas (FACON, 2006, p. 653). Em 2000, já na qualidade de Presidente da Rússia, uma das primeiras medidas tomadas por Putin consisitiu no reforço da integração e da cooperação no seio da Comunidade de Estados Independentes (CEI). Para Raquel Freire (2012), "a Rússia de Putin procura equilibrar os seus interesses eurasiáticos com a sua política face ao Ocidente”. Com 
efeito, "desde o primeiro mandato de Putin que a política multivetorial da Rússia se consolidou”, ou seja, a Moscovo interessa não só "o espaço pós-soviético, mas também as relações com o Ocidente e com a Ásia, e, aqui, a China e a Índia" (FREIRE, 2012). A Organização de Cooperação de Xangai reflete e serve, simultaneamente, de instrumento a esta política multivetorial de Moscovo.

Desde os anos 90 que tem lugar, na Rússia, um processo notável de reorganização do setor energético, o qual ganhou um dinamismo particular sob a liderança de Putin. Esta reestruturação tem como principais objetivos: atrair investimento estrangeiro; tornar a indústria mais competitiva; estabelecer parcerias a longo prazo com as principais regiões consumidoras de energia, nomeadamente o leste asiático e a Europa; bem como expandir e consolidar os interesses económicos e estratégicos russos na Ásia Central e no Golfo Pérsico. (BAHGAT, 2003, p .31)

Contrariamente à era Yeltsin, em que os oligarcas e as empresas privadas utilizavam, com frequência, os recursos energéticos em benefício individual, "o apoio de Putin às privatizações como que inverteu todo o processo, com o objetivo de priorizar também os interesses governamentais" (MAMMADOV, 2009, p. 87). Por outro lado, é de sublinhar que, ao contrário de Boris Yeltsin, Putin decidiu apostar na redefinição da política russa face ao Cáspio. Na prática, Putin pediu à indústria que se envolvesse, de forma mais ativa, na exploração energética no Cáspio, e que assumisse, igualmente, uma postura mais cooperativa face à intenção de outros países (competidores da Rússia, por conseguinte) investirem, também, no Cáspio. Por outro lado, vários especialistas acreditam que

a política de Putin face ao Cáspio se afastou da tentativa de contenção da expansão norte-americana na região, em favor de um 'compromisso construtivo' face ao Governo norte-americano e às companhias petrolíferas [internacionais]. (BAKER INSTITUTE, 2000, p. 10).

À luz desta nova política, mais coerente e assertiva que a de Yeltsin, as maiores companhias russas de petróleo e gás natural - Lukoil, Yukos, e a Gazprom - "uniram-se e formaram a Caspian Oil Company", em 2000, para ajudar a Rússia a reforçar a sua posição na região (SAIVETS, 2000, p. 59). Acrescente-se que, "pela primeira vez, a Rússia procurou uma nova perspetiva com vista à resolução da difícil questão do estatuto do Mar Cáspio", com o intuito de permitir aos Estados litorais desenvolver "uma cooperação mútua a respeito da exploração dos recursos da região, numa base equitativa, tomando em consideração os legítimos interesses de cada parte" (IVANOV, 2000, p. 51).

\section{Notas finais}

Procurou-se descrever os interesses da União Europeia e da Rússia na Ásia Central como sendo impregnados de um certo realismo. Na verdade, quisemos explicar que o desejo de reforço das relações com as cinco Repúblicas centro-asiáticas gravita essencialmente em torno de uma busca de poder, cara ao realismo. Todavia, o poder é aqui entendido como um poder 'energético', que se sobrepõe, por exemplo, ao tradicional poder 'normativo' da União Europeia. Afinal de contas, países timoneiros como a Alemanha ou a França não estão fundamentalmente preocupados com a questão dos direitos humanos ou da democracia no seu trato com as Repúblicas centro-asiáticas, mas sim com o esboçar de uma estratégia, ainda que incipiente, que confere a primazia à questão energética. A Rússia, ao invés da União Europeia, manifesta uma estratégia relativamente consolidada face à região, já que, como explicámos, esta é o 'estrangeiro próximo' de Moscovo, que fora, outrora, o colonizador. No entanto, à semelhança da União Europeia, Moscovo também procura colocar na dianteira dos seus objetivos a questão económica, entenda-se energética, não obstante a segurança física ser naturalmente importante nesta região periférica. Em síntese, europeus e russos têm diferentes histórias, diferentes percursos, mas uma necessidade veemente de recursos energéticos. A procura realista do poder encontra, desta forma, a sua expressão máxima na vertente energética, o poder energético, através da tentativa de securitizar o abastecimento de petróleo e gás natural.

\section{Referências}

AUBERT, Laurène. The European Union's Policy towards Central Asia and South Caucasus: a Coherent Strategy?, Bruges Regional Integration \& Global Governance Papers, v. 1, p. 4-30, 2012.

BAHGAT, Gawdat. American Oil Diplomacy in the Persian Gulf and the Caspian Sea. Florida: University Press of Florida, 2003. 
BBC NEWS ASIA. Kyrgyzstan profile. October 10, 2012. BBC.com. Disponível em: <http://www.bbc.co.uk/news/ world-asia-16186907>. Acesso em: 13 jun. 2014.

BBC NEWS ASIA. Turkmenistan Profile. October. 17, 2012. BBC.com. Disponível em: <http://www.bbc.co.uk/ news/world-asia-16094646>. Acesso em: 10 jun. 2014.

BELTON, Catherine. Caspian Great Game Back on. Moscow Times, May 5, 2006

BLANK, Stephen. Central Asian Security Trends: views from Europe and Russia. Strategic Studies Institute, 2011.

BLANK, Stephen. Every shark east of Suez: great power interests, policies and tactics in Transcaspian energy wars. Central Asian Survey, v. 18, n. 2, p. 149-184, 1999.

BOONSTRA, Jos et al. The EU Strategy for Central Asia says 'security'. Does this include Security Sector Reform? Policy Brief, EU-Central Asia Monitoring, v. 10, p. 4-124, 2009.

BOONSTRA, Jos; EMERSON, Michael. Into EurAsia: Monitoring the EU's Central Asia Strategy. Brussel/ Madrid: Centre for European Policy Studies (CEPS) and Fundación para las Relaciones Internacionales y el Diálogo Exterior (FRIDE), 2010.

BRZEZINSKI, Zbigniew. The Grand Chessboard: American Primacy And Its Geostrategic Imperatives. New York: Basic Books, 1998.

BUCKLER, Ann. What comes after 'Post-Soviet' in Russian studies?. PMLA, v. 124, n. 1, p. 251-263, 2009.

BUZAN, Buzan. People, states and fear: an agenda for international security studies in the post-Cold War. London: Hasvester Wheatsheaf, 1991.

CLANCY, Stephanie. Pipeline projects in the Middle East, Pipelines International. 2010. Disponível em: <http:// pipelinesinternational.com/news/pipeline_projects_in_ the_middle_east/040183/>. Acesso em: 09 jun. 2014.

CORNELL, Svante. Commentary, so far, Europe's approach to Central Asia has been moralistic and counter-productive. Europe's World, v. 5, p. 16-21, 2007.

DU, Ruoxi. Central Asian Energy: A Point of Contention or Collaboration in Russia-China Relations. CREESFMSO. 2011

EDWARDS, Mattew. The New Great Game and the new great gamers: disciples of Kipling and Mackinder. Central Asian Survey, v. 22, n. 1, p. 83-102, 2003.
EMERSON, Michael et al. Into Eurasia Monitoring the EU's Central Asia Strategy. Brussels/Madrid: CEPS/ FRIDE, 2010.

EMERSON, Michael. From Central Asian Strategy into EurAsian Strategy. Brussels: Centre for European Policy Studies, 2009.

EUROSTAT. Energy Production and Imports. Data from August 2012, European Commission Eurostat. Disponível em: <http://epp.eurostat.ec.europa.eu/ statistics_explained/index.php/Energy_production_ and_imports\#Further_Eurostat_information>. Acesso em: 03 jun. 2014.

FACON, Isabelle. Les relations stratégiques Chine-Russie en 2005: la réactivation d"une amitié pragmatique. Fondation pour la Recherche Stratégique, 2006

GARIBOV, Azad. Russia and Central Asia: Do all Central Asian roads still lead to Russia? The Journal of Turkish Weekly, Turkish Weekly.net: Disponível em: <http://www. turkishweekly.net/news/149055/russia-and-central-asiado-all-central-asian-roads-still-lead-to-russia.html> . Acesso em: 11 jun. 2014.

GIRAGOSIAN, Richard. The Strategic Central Asian Arena. China and Eurasia Forum Quarterly, v. 4, n. 1, p. 133-153, 2006.

GORST, Isabel. Struggle for Gas Intensifies. Petroleum Economist, v.73, n. 5, p. 12-40, 2006.

HUNTER, Shireen. Central Asia since independence. London: Praeger. 1996.

IVANOV, Igor. Vneshnyaya Politika Rossii na Sovremennom Etape. Moskva: 2000.

KEOHANE, Robert. Realism, Neorealism and the Study of World Politics. New York: Basic Books, 2000.

LARUELLE, Marlène. Russia in Central Asia: Old History, New Challenges?, EUCAM Working Paper, v. 3, p. 4-11, 2009.

LIVANIOS, Anthony. The Conundrum of the Southern Gas Corridor: What are the Risks for Europe and Azerbaijan? The viewpoint of an insider, Institut Français des Relations Internationales, v. 3, p. 1-18, 2012.

LUFT, Gal; KORIN, Anne. Energy Security Challenges for the 21 $1^{\text {st }}$ Century: A Reference Handbook. Contemporary Military, Strategic, and Security Issues. Westport: Praeger Security International, 2009.

MACKINDER, Halford. The geographical pivot of history. The Geographical Journal, v. 170, n. 4, p. 298-321, 2004. 
MAMMADOV, Ilgar. Geopolitics of Energy in the Caspian Sea Region: Azerbaijan's Challenges, Master of Arts Thesis, presented at Tufts University, 2009.

MELVIN, Neil. Engaging Central Asia: The European Union's New Strategy in the Heart of Eurasia, Centre for European Policy Studies. 2008.

MORGENTHAU, Hans. Politics Among Nations: The Struggle for Power and Peace. $5^{\text {th }}$. New York: Alfred A. Knopf, 1978.

NICHOL, Jim. Turkmenistan: Recent Developments and U.S. Interests. CRS Report for Congress, 2012.

PEYROUSE, Sébastien, et al. Security and development approaches to Central Asia. The EU compared to China and Russia. EUCAM Working Paper, v. 11, p. 3-24, 2012.

RATNER, Michael et al. Europe's Energy Security: Options and Challenges to Natural Gas Supply Diversification. CRS Report for Congress, 2013.

ROUSSEAU, Richard. Germany's Changing Role in Central Asia. The Washington Review of Turkish and Eurasian Affairs, The Washington Review. 2012. Disponível em: <http://www.thewashingtonreview.org/ articles/germanys-changing-role-in-central-asia.html $>$. Acesso em: 19 jun. 2014.

ROUSSEAU, Richard. Pipeline Politics in Central Asia, Foreign Policy in Focus. 2011. Disponível em: <http:// www.fpif.org/articles/pipeline_politics_in_central_asia $>$. Acesso em: 18 jun. 2014.

ROWLEY, Mark. The Nabucco Pipeline Project-Gas Bridge to Europe. Pipeline and Gas Journal, v. 236, n. 9, 2009.

SAIVETZ, Carol. Caspian Geopolitics: The View from Moscow. The Brown Journal of World Affairs, v. 7, n. 2, p. 53-61, 2000.

SANTOS, Victor. Introdução à Teoria das Relações Internacionais. Referências de Enquadramento TeóricoAnalítico. Lisboa: Instituto Superior de Ciências Sociais e Políticas, Universidade Técnica de Lisboa, 2007.

SHEVTSOVA, Lilia. Russia XXI: The Logic of Suicide and Rebirth. Moscow: Carnegie Endowment for International Peace, 2013.

SIITONEN, Lauri. Political Theories of Development Cooperation: A Study of Theories of International Cooperation. Helsinki: World Institute for Development Economics Research of the United Nations University, 1990.
THE WASHINGTON POST. President Bush's State of the Union Address. January 31, 2006. The Washington Post. Disponível em: <http://www.washingtonpost.com/ wp-dyn/content/article/2006/01/31/AR2006013101468. html>. Acesso em: 23 jun. 2014.

TOMÉ, Luís. O Grande Jogo Geopolítico nos Espaços do 'Espaço Pós-Soviético'. Geopolítica, v. 1, p. 187-240, 2007.

TORBAKOV, Igor. From hegemony to the new geopolitical competition. Helsinki: The Finnish Institute of International Affairs, 2008.

TSYGANKOV, Andrei. Preserving Influence in a Changing World: Russia's Grand Strategy. Problems of Post-Communism, v. 58, n. 1, p. 28-44, 2011.

U.S. ENERGY IINFORMATION ADMINISTRATION. Kazakhstan, Full Report. September 4, 2012. EIA. gov. Disponível em: <http://www.eia.gov/countries/ analysisbriefs/Kazakhstan/kazakhstan.pdf>. Acesso em: 30 jun. 2014.

VATANSEVER, Adnan. Russia's Oil Exports. Economic Rationale Versus Strategic Gains. Carnegie Papers, 2010.

WINROW, Gareth. Problems and Prospects for the 'Fourth Corridor': the positions and the role of Turkey in gas transit to Europe. Oxford: Oxford Institute for Energy Studies, 2009.

WUNDERLICH, Jens-Uwe and BAILEY, David. The European Union and global governance, London: Routledge international handbooks, 2011.

YERGIN, Daniel. Ensuring Energy Security. Foreign Affairs, v. 85, n. 2, p. 69-82, 2006.

\section{Agradecimentos}

Um sincero obrigado à Fundação Calouste Gulbenkian pela bolsa de doutoramento que me concedeu pela mão do então Presidente Dr. Emílio Rui Vilar, prolongada posteriormente pelo Presidente Dr. Artur Santos Silva.

Um agradecimento também à Rede Aga Khan para o Desenvolvimento cujo Alto Representante em Portugal, Exmo Comendador Dr. Nazim Ahmad, proporcionou a necessária assistência técnica aquando das minhas duas deslocações ao terreno centro-asiático (Cazaquistão, Quirguistão e Tajiquistão). 